\title{
Non-Representational Ethnography: New Ways of Animating Lifeworlds
}

Ethnographic approaches have long been a staple of research in geography. ${ }^{1}$ However, over the last decade social and cultural geographies have witnessed a genuine explosion of interest in this tradition. Several progress reports, review articles, and methodological books have paid close attention to evolving ethnographic styles, techniques, concerns, and quality criteria. ${ }^{2}$ Such interest is due in great part to the increasing acceptance of non-representational ideas across the field and the way these ideas have constructively informed the long-standing debate on the analytics, aesthetics, and politics of ethnographic representation-a debate which originated with Clifford and Marcus's ${ }^{3}$ edited reflection on the limits of ethnographic authority and then continued unabated up to the first decade of the new millennium. ${ }^{4}$

In this paper I focus on five ways in which non-representational theoretical ideas have influenced geographical ethnography. These ways correspond to five qualities of what we might call nonrepresentational ethnography: vitality, performativity, corporeality, sensuality, and mobility. My list of qualities is not exhaustive; there are presumably many other arguably equally important qualities that I have no space no discuss here. These five qualities are also non-mutually exclusive and clearly subject to varying definitional interpretations and applications subject to all the disagreements typical of a constantly evolving style. ${ }^{5}$ For better or for worse these five qualities are simply the outcomes of my informed but highly subjective reading of the last ten years of non-representational ethnographic research studies. ${ }^{6}$ These are empirical studies, to be transparent, that either explicitly recognize their non-representational inspiration through citations of the 'new classics' of this tradition, or that implicitly manifest sympathy with these ideas by subtly adopting them as their epistemological or methodological inspiration.

I define ethnography as people-focused emic research which makes use of data collection methods such as participation, observation, and interview, and which unfolds by way of thick description and interpretive contextualization. Whereas traditional and realist ethnography more-or-less posit the representation of their research subject(s) as a faithful rendition of the word 'as is', non-representational ethnographers consider their work to be impressionistic and inevitably creative, and though they are inspired by their lived experiences in the field they do not claim to be able, or even interested, in reporting 
on those in an impersonal, neutral, or reliable manner. Thus, non-representational ethnographic styles can be said to be styles that strive to animate rather than simply mimic, to rupture rather than merely account, to evoke rather than just report, and to reverberate instead of more modestly resonating, in this sense offering a true 'escape from the established academic habit of striving to uncover meanings and values that apparently await our discovery, interpretation, judgement and ultimate representation. ${ }^{8}$ In what follows I attempt to capture some (by necessity selected) examples of non-representational ethnography, especially chosen in relation to their rhetorical characteristics (as opposed to issues of gaining access to the field, collecting data, conducting ethical research etc.), as it is in this regard that the impact of nonrepresentational theory is more strongly felt. I begin with an overview of the ideas underlying nonrepresentational methodologies.

\section{Doing Research Non-Representationally}

Despite its many permutations non-representational theory generally calls for 'diverse work that seeks to better cope with our self-evidently more-than-human, more-than-textual, multisensual worlds. ${ }^{9}$ Calling for resolutely experimental research that eclectically synthesizes the cultural sciences with philosophy, the arts, and humanities, non-representational theory (not unlike ethnography) aims to be an interpretive 'supplement to the ordinary, a sacrament for the everyday, a hymn to the superfluous. ${ }^{10}$ As it continues to mature, non-representational research seeks to cultivate an affinity for the analysis of events, practices, assemblages, affective atmospheres, and the backgrounds of everyday life against which relations unfold in their myriad potentials. As it evolves, non-representational research continues to emphasize the fleeting, viscous, lively, embodied, material, more-than-human, pre-cognitive, non-discursive dimensions of spatially and temporally complex lifeworlds." Non-representational ethnography in particular attempts to grapple with the challenge of sharing empirical narratives that make sense-or that, in other words, are inspired by and feel coherent with the world as encountered-while simultaneously underscoring the situatedness, partiality, contingency, and creativity of that sense-making. Arguably, one flippant way of putting it might be to quip that non-representational ethnography does not represent but instead 'flirts' ${ }^{912}$ with reality. 
Even though there are no magic ingredients for an 'authentic' non-representational ethnography recipe several points of agreement amongst non-representational writers can be gleaned. For example, as Latham $^{13}$ argues, the point of departure must be a fight against methodological timidity. Timidity is difficult to define but easy to recognize. Thrift ${ }^{14}$ finds the prototypical expressions of timidity in the interview and ethnographic data 'nicely packaged up in a few supposedly illustrative quotations' commonly displayed in qualitative research articles and more broadly in the 'know and tell ${ }^{15}$ mode typical of traditional qualitative research. However, the problem is less inherent in the method itself (after all good ethnography is meant to 'show' and not to 'know') and more in the actuality of practicing it. A wider range of writing genres and styles than those most typically found in traditional journals can in fact allow researchers to engage in more creative and more performative practices.

To this effect, Dewsbury ${ }^{16}$ calls for the disruption of research habits and for novel expressions of creativity. For him the key to combatting timidity lies in making research more performative. This does not necessarily mean staging research and acting out findings in a theatre, but in striving to find inspiration in the arts, in the poetics of embodied living, in enacting the very un-actualized expressive and impressive potentials of social-scientific knowledge, in taking dedicated risks, in exercising passion, and in finding ways to re-configure thinking, sensing, and presenting by emphasizing the singular powers of action, locution, and thought.

Like Dewsbury, Latham argues that new styles can draw inspiration from the sensuous, embodied, 'non-cognitive, preintentional, and commonsensical' ${ }^{17}$ practices of everyday life, as these are laden with creativity and possibility. As he writes:

I want to suggest that, rather than ditching the methodological skills that human geography has so painfully accumulated, we should work through how we can imbue traditional research methodologies with a sense of the creative, the practical, and being with practice-ness that Thrift is seeking. Pushed in the appropriate direction there is no reason why these methods cannot be made to dance a little. ${ }^{18}$ 
Of course the nature of the 'the appropriate direction' is truly the question. For Thorpe and Rinehart $^{19}$ the direction is affective, kinesthetic, and sensuous. For Laurier and Philo ${ }^{20}$ the direction is that of seeking what more and what else can be said through instance of language in use. For Hinchcliffe ${ }^{21}$ the direction is toward the gaps of knowing and in the unsaid. For Pink ${ }^{22}$ a possible direction lies in going beyond the written traces of the book, toward the realm of the multimodal. For Ingold ${ }^{23}$ it is in new traces of the pen, like drawing and sketching, whereas for Stewart ${ }^{24}$ and $\mathrm{Wylie}^{25}$ and myself ${ }^{26}$ the key is in performative writing. In sum, if we can once again engage the well-known expression, the idea is to make our ethnographic research 'dance a little.'

To 'dance a little' may entail a greater focus on events, affective states, the unsaid, and the incompleteness and openness of everyday performances-something that is beginning to characterize nonrepresentational research style writ large and well beyond the traditional definitional boundaries of ethnography. The key distinction of all these approaches is that-in the words of Dewsbury ${ }^{27}$-they relish the failures of knowledge. Manning ${ }^{28}$ as well as Doel $^{29}$ for example incite researchers to embrace experimentation, to view the impossibility of empirical research as a creative opportunity (rather than a damming condition), to unsettle the systematicity of procedure, to reconfigure (rather than mimic) the lifeworld, and in sum to learn to fail, to fail better.

The non-representational idea that there are other and diverse ways of knowing, and especially of knowing ethnographically, is perhaps more than anything else at the core of the ethos of animation. By 'animating' lifeworlds non-representational ethnographic styles aim to enliven, render, resonate, rupture, reimagine, and to generate possibilities for fabulation. If indeed there is a quintessential non-representational style, then it is that of becoming entangled in relations and objects, rather than studying their structures and symbolic meanings ${ }^{30}$, thus animating the potential of these meshworks for our geographical imagination. Let us know take a brief look at five of the ways in which animation takes place in non-representational ethnographic composition.

\section{Animating Non-representational Ethnographies}

\section{Vitality}


Everyday life is a mix of taken-for-granted realities, habit, and routine as well as impulse, novelty, and vivaciousness. Realist representational research typically downplays the latter characteristics and marginalizes them as exceptions to an ordered world-thus portraying social existence through the lenses of rational behavior, politico-economic causation, cognitive planning, instrumental interaction, and mechanistic predictability. Instead, non-representational research renders the liveliness of everyday interaction through methodological strategies that animate, rather than deaden, the qualities of the relation among people, objects, organic matter, animals, and their natural and built environments. In other words, nonrepresentational ethnographies aim to be as full of vitality as the lifeworlds they endeavor to enact.

Vitalist approaches argue that there is an exceptional quality to life: a certain impetuous ardor possessed by both inanimate and animate beings ${ }^{31}$ which makes life unexplainable by deterministic laws of prediction. As a result non-representational ethnographies are restless, rich with verve and brio, constantly on the move, forever becoming something else, something originally unplanned. This is something that demands and fosters a new vitalist 'material imagination,' something that re-imagines both human and 'nonhuman materialities as animated by dynamic and lively capacities to affect change and to participate in political life. ${ }^{32}$ Non-representational ethnographers are therefore less interested in coding textual data to give rise to explanatory descriptive categories than they are in acknowledging the very limitations of their own understanding of the world and in the enchanting processes through which life constantly mystifies us.

The idea of vitality 'makes a particular sort of demand on the researcher to attend to the complexity and indeterminacy of things in the world ${ }^{33}$ and non-representational ethnographers therefore view fieldwork encounters as exceeding representation and explanation: as events through which they and their informants make and remake their lifeworlds through their changing positions and relations. ${ }^{34}$ This is the case, for example, with the 'mysterious effect ${ }^{35}$ of so-called 'inanimate' things like music. In Saldanha's analysis of the trance scene in Goa music 'changes people and circumstances, and it changes different people in different ways, according to differences in race, gender, and class. ${ }^{36}$ Similarly, things like walls, stairways, and roof gaps-as depicted in Saville's ${ }^{37}$ study of parkour-'become real' when methods focus on how people can move with-not on or through, but 'with'-them. A vitalist ethnography, in short, is an ethnography pulled 
and pushed by a sense of wonder and awe with a world that is forever escaping, and yet seductively demanding, our comprehension.

\section{Performativity}

Non-representational ethnography zeroes in on what actors $d o$, as much as what they attempt to do and fail to do. This focus on action-by people and other actors-emphasizes the importance of ritualized performances, habitual and non-habitual behaviors, play, and the various scripted and unscripted, uncertain and unsuccessful doings of which everyday life is made, no matter how seemingly mundane or unimportant. Performativity $^{38}$ does not mean, exclusively, that life is a stage-in the dramaturgic, Goffmanian sense. Nonrepresentational ethnographers are not necessarily interested in going behind the 'masks' the subjects wear or in digging out authentic meanings hidden behind stage. While interaction at times does have dramatic qualities, the idea of performativity underlines the broader relevance of concerted actions-or 'events'-in our mundane existence and their fragility and-at times-inscrutability.

Take for instance Laurier and Philo's ${ }^{39}$ 'undefined investigation' of a simple passing encounter in a café. By positing a passing encounter as a singular event situated at the faultline of representational language and the unspeakable impasses and silences of everyday unwriteable and unrepresentable interaction, Laurier and Philo find that the performative nature of ordinary speech challenges non-representational researchers to inhabit an aporetic space marked by doubt and possibility. Or consider how in Rose's ${ }^{40}$ ethnography of 'New Age' pilgrims on a visit to Egypt identity is not performed, or shown off, as something people have in order to display to others for validation. Identity, instead, is something given, something primordially and somehow mysteriously cast upon a subject by voices calling from the outside. Ethnography then in this case is not so much undertaken to explain but rather to make audible silences and invisible forces, to perform 'a presence that presents itself as an absence, a nagging question, a distant calling whose contours remain wholly obscure'. ${ }^{11}$

Being sensitive to the quality of performativity means tuning-in to the event-ness of the world, ${ }^{42}$ taking a witness stance to the unfolding of situated action, ${ }^{43}$ and being open to the unsettling co-presence of bodies affecting each other in time-space. ${ }^{44}$ An ethnographic attention to performance then is an attention to 
identity performances, border-crossings, processes, contingencies, struggles, passions, improvisations, shifting subjectivities, and practices of all kinds. This is not the same as to say that non-representational ethnographies are performances. Performance ethnography is a distinct research strategy ${ }^{45}$ with unique modalities of expression that are not typically accommodated by the written page. Yet, non-representational ethnographies attempt to be performative in style by privileging 'particular, participatory, dynamic, intimate, precarious, embodied experience grounded in historical processes, contingency, and ideology' and by 'tak[ing] as both its subject matter and method the experiencing body situated in time, place, and history. ${ }^{, 46}$

\section{Corporeality}

Our presence in the world is embodied. Non-representational ethnographic research begins from the researcher's body as the key instrument for knowing, sensing, feeling, and relating to others and self. Passions, orientations, moods, emotions, sentiments, sensations, dispositions, colors, sizes, shapes, and skills work as the bodily fluids enlivening all relations in which ethnographic relations are entangled. From fatigue to enthusiasm, melancholia to keenness, pain to enchantment, non-representational ethnographic research is affected by bodies' capacity to affect the world and their capacity to be affected by it.

Affect, of course, is a central topic in non-representational scholarship. ${ }^{47}$ But to say that nonrepresentational ethnography focuses on affect as a subject of research is not the same as to suggest that affect is a medium through which ethnographic research unfolds. Put in other words, it is not enough for non-representational ethnography to be about affect; it must also be affective. One the most affective writers is anthropologist Kathleen Stewart, whose recent work has become quite influential in geography. ${ }^{48}$ Stewart writes from the heart, from her embodied presence in the 'field,' from being entangled in the very world she re-creates anew with her words. Her seemingly random sketches of everyday life in the United States 'loosen the formal narratives [...] and the heavy presumptions of a proper and automatic relationship between thinking subject, object, and world. ${ }^{99}$ Her ethnographic narratives weave theory and empirical material seamlessly, tying together strands of observation and interpretation. Affect, in her pages, comes to life through conceptual pauses as much as through descriptive interventions. ${ }^{50}$ Her stories affect us carnally, employing theory not as a cognitive weapon but as a touching composition of what is happening, what is 
hanging in the air. These are rare, beautiful rhetorical strategies employed by other non-representational writers $^{\text {s1 }}$ as well who are equally keen on using powerful storytelling to create emotional openings and move readers to feel something, rather than just think about it.

The corporeality of non-representational work most often comes through in ethnographies focused on body-centered activities that require the performance of skill, temporal sensitivity (e.g. rhythm), and kinaesthetic awareness (e.g. choreographed movement). For example Simpson's ${ }^{52}$ rhythmanalysis of street performance allows the reader to come to terms with bodies taking place through live, dramatically intense physical performances. Rhythmic considerations are also at the center of Reville's ${ }^{53}$ autoethnographic notes on the practice of French Folk music. Reville's attention on the corporeality of music as a carnal experience unfolding through space-rather than, say, a genre or a text-reveals 'the impact of rhythm, timbre, and melody on the body, highlighting the ways in which the physical practice of music shapes its aesthetic forms and social spaces'. ${ }^{54}$ Similar to Reville's study in its orientation to communication as a place-based performance rather than a disembodied text Rogers's $\mathrm{s}^{55}$ ethnographic investigation of a theatrical performance shows how scripts are material, affective, and embodied.

\section{Sensuality}

Lifeworlds are endowed with a fleeting qualitative immediacy that individuals encounter through embodied, practical, meaningful, sensory orientations. ${ }^{56}$ These orientations are intentional, but not always reflexive in a cognitive way. Non-representational ethnographies underline the not-necessarily reflexive sensory dimensions of experience by paying attention to the perceptual dimensions of our actions and the habituated and routine nature of everyday existence. In doing so, they engage in sensuous scholarship: research about the senses, through the senses, and for the senses. ${ }^{57}$ Sensuous scholarship invites us to appreciate the meaningfulness of our sensory experience of the world, the importance of the skilled practices through which we make sense of the lifeworld through our senses, and the value of the evocativeness of our strategies of animation..$^{58}$

The sensuality of non-representational ethnographies depends on a re-awakened scholarly body: a body 'stiffened from long sleep in the background of scholarly life' that now 'yearns to exercise its muscles,' 
and 'aches to restore its sensibilities ${ }^{59}$ by opposing the dullness of overly analytic, formal, anonymous, and unimaginative scholarship. ${ }^{60}$ In 'Surfaces and Slopes,' for example, Hayden Lorimer $^{61}$ relies on a poetic essay memoir to describe the sensory work of running as an exploration of differently-textured terrains and trails. In this beautiful essay Lorimer speaks through the feet, as it were, allowing thick carnal description to take precedence over any sort of theorizing, lengthy introductions, and detached conclusions. Lorimer's delightful approach is as exemplary in its more-than-representational richness as it is rare-for much too often sensuous writing is still book-ended by the prescriptions of formal and traditional scholarship.

It seems as though sensuous geographers who aren't running, are walking. The slow rhythms of walking, arguably, allow for ethnographies that are sensitive to spatial details and to the rhythmic pauses, stops, and re-starts of sensuous observation and reflection. In the case of Morris ${ }^{62}$ darkness goes a long way too. In her fieldwork on the Isle of Skye Morris's own body, as well as The Storr Art Installation participants' bodies, are forced to come to terms with their dark surroundings as they walk in the woods at night. Morris's writing reveals the unsettling character of the experience, designed to lessen the ocularcentricity of landscape and to awaken the other senses. Also walking along others-for a research project aimed at understanding how legacies of the past generate affective registers capable of evoking and unsettling senses of place and time-Hill's writing builds a narrative of the past 'that attends to the discursive and embodied conditions of its existence in the present' and to 'highlight the matter that brings forth memories, ${ }^{, 63}$ skilfully blurring the boundaries between the present and absent as sensed.

\section{Mobility}

Fieldwork generally entails travel and ethnography in the end, perhaps, is little more than a glorified form of travel-writing. Mobile ethnographies have thus begun to make sense of the itinerant and kinaesthetic aspects of fieldwork and to portray ethnographic work as happening on the move. ${ }^{61}$ Non-representational ethnography is particularly well-equipped to handle the kinetic dimensions of fieldwork-as several of the examples cited thus far have evidenced. Drawing attention to movement is important not only because it evokes the perambulations of ethnographers in all their vicissitudes and complex logistical relations, but also because doing so situates fieldwork in the concrete time-spaces that ethnographers actually inhabit. In fact, 
all fieldwork unfolds in space and time and as a result ethnographies are positionings, orientations, and travails always busy with securing the loss of old habits and coming to terms with being out of place. 'Inhabiting space,' like ethnography, 'is both about finding our way and how we come to feel at home. ${ }^{9_{5}}$ Like all forms of travel, therefore, non-representational fieldwork engages us-as practitioners and audiences-as a constant re-negotiation of difference and repetition, of the ordinary and unfamiliar.

Building from Ingold's ${ }^{66}$ ideas on movement we might then characterize non-representational ethnography as a practice of wayfaring. From this perspective ethnographic journeys are not planned transitions from the office to the field site but wanderings through which movement speaks. These wanderings are also wonderings which seek out the interweaving storylines binding self, others, places, and times-lines which, just like ethnographic travel, are dynamic, unpredictable, with no clear roots or obvious boundaries or ends. Through journeying as storytelling non-representational ethnographers take storylines in flight, out for a walk, along on a paddle, forming 'knot[s] tied from multiple and interlaced strands of movement and growth. ${ }^{97}$ Wylie's often cited treks are a wonderful example of how writers can animate the landscape, ${ }^{68}$ but other, less-known but equally exquisite examples exist. In a recent writing Lingis ${ }^{69}$ narrates momentous journeys-like solitary yearlong bike rides, a deadly walk from Perth to Adelaide-to consecrate personal losses. His evocative writing, like every loss he tells, leaves voids and after-images that are meant to ring hollow, struck with nothingness, perhaps simply driven by nothing other than the irrational will to take the line for a walk.

Not everything that is moored is immobile. Stewart's ${ }^{70}$ recent examination of road registers animates the American road as 'a registering form in which intensities lodged in institutional effects and lived affects, materialities and dreamworlds, differences and energies, reach a point of expressivity and become legible.' Stewart's masterful writing achieves this effect via experimental snapshots taken with varying rhythms, tones, and orientations. Sliding away from realism entirely, and toward what she calls creative non-fiction or fictocritical, Stewart's writing slows down and speeds up, then decelerates and accelerates again, enlivening a feeling of being on the road. Another example of rich kinaesthetic animation comes from, once again, Hayden Lorimer and John Wylie ${ }^{71}$ as part of a unique trek the two undertook en route to Aberystwyth, being at times apart, at times together, and setting out from different 
points. Their blended narrative, denuded of the compartments typically comprising the organization of academic papers, unfolds by location-with coordinates setting the pace of their tale and the various sections of their writing. More radically experimental than most, Lorimer and Wylie's writing utilizes short sentences that give a sense of their economy of breath, echoing the brief sounds felt in the landscape, as much as the quiet through which they moved.

\section{Afterthought}

As Cresswell ${ }^{72}$ notes in a recent review of Anderson and Harrison's Taking Place: Non-Representational Theories and Geography, non-representational ideas can at times be 'infuriating.' In part this is because of the school of thought's inherent limitations. Most notably non-representational scholarship is still not sufficiently diverse in terms of gender, disciplinary, and international membership; not sufficiently concerned with power, injustice and politics; not well-aware of its humanistic lineage; not reflexive enough toward recognition of its own intertextuality and citationality; not consistently clear and accessible for all; and not conceptually coherent on issues of agency, non-relationality, obduracy, and subjectivity. But also in part, as Cresswell finds, non-representational scholarship is infuriating because of its internal heterogeneity. And how could it not be, given Thrift's lexical grouping of perspectives as diverse as actor-network theory, phenomenology and post-phenomenology, ethnomethodology, pragmatism, post-structuralism, process philosophy, social ecology, feminism, performance theory, object-oriented ontology, and speculative realism?

With all this in mind I want to conclude this brief writing with a recognition of the limitation of this review; with a negation, if you will, of the artificial tidiness, clarity, organizational efficiency, and linearity that I have imposed (for the sake of intelligibility and brevity) on this complex perspective. As well, I want to conclude by inciting those who are interested in non-representational scholarship to be more skeptical toward its consistency, applicability, coherence, and usefulness than they might be. Not because in the end I do not really value non-representational ideas, but because I want to be mindful of the dangers of forming new canons (as this paper might inevitably contribute to) and the perils of eliding the numerous disagreements existing over nuanced ideas underlying the five qualities I much too briefly outlined here. Non-representational scholarship is borne out of a disorderly will to experiment and to fail-indeed to try 
and continue to fail better. Along these lines I wish to end by urging readers and writers keen on transcending the limits of representationalism to break rules and to think, feel, and write differently. And to cultivate heterogeneity. And to never be afraid of being a little infuriating.

\section{Acknowledgement}

I wish to thank the editors and reviewers of this paper, who have given me wonderful suggestions for improving my work.

\section{Biographical note}

Phillip Vannini is Canada Research Chair in Innovative Learning and Public Ethnography, and Professor in Communication and Culture at Royal Roads University. His interest in non-representational ethnography is manifested in books such as Ferry Tales (Routledge, 2012), and Off the Grid (Routledge, 2014). He is also editor of Non-Representational Methodologies: Re-Envisioning Research (Routledge, 2014).

\footnotetext{
${ }^{1}$ M. Cope, 'A History of Qualitative Research in Geography', in D. DeLyser, S. Herbert, S. Aitken, M. Crang, L. McDowell, The SAGE Handbook of Qualitative Geography (London: SAGE, 2009), pp. 25-46. D. DeLyser, S. Herbert, S. Aitken, M. Crang, L. McDowell, 'Introduction: Engaging Qualitative Geography', in D. DeLyser, et al., The SAGE Handbook of Qualitative Geography, pp. 1-19.

${ }^{2}$ M. Crang, 'Qualitative Methods: The New Orthodoxy?', Progress in Human Geography, 26, 2002, pp. 647-655. M. Crang, 'Qualitative Methods: Touchy, Feely, Look-See?', Progress in Human Geography, 27, 2003, pp. 494-504. M. Crang, 'Qualitative Methods: There Is Nothing Outside the Text?', Progress in Human Geography, 29, 2005, pp. 225233. D. DeLyser et al., The SAGE Handbook of Qualitative Geography. G. Davies and C. Dwyer, 'Qualitative Methods: Are You Enchanted or Are You Alienated?', Progress in Human Geography, 31, 2007, pp. 257-266. G. Davies and C. Dwyer, 'Qualitative Methods II: Minding the Gap', Progress in Human Geography, 32, 2008, pp. 399406. C. Dwyer and G. Davies, 'Qualitative Methods III: Animating Archives, Artful Interventions, and Online Environments', Progress in Human Geography, 34, 2009, pp. 88-97. M. Paterson, 'Haptic Geographies: Ethnography, Haptic Knowledges, and Sensuous Dispositions', Progress in Human Geography, 33, 2009, pp. 1-23. A. Watson and K. Till, 'Ethnography and Participant Observation', in D. DeLyser et al., The SAGE Handbook of Qualitative Geography, pp. 121-138.
}

${ }^{3}$ J. Clifford and G. Marcus (eds.), Writing Culture (Berkeley: University of California Press, 1986).

'J.D. Dewsbury, 'Performative, Non-Representational, and Affect-Based Research: Seven Injunctions', in D. DeLyser et al., The SAGE Handbook of Qualitative Geography, pp. 321-333. A. Latham, 'Research, Performance, and Doing 
Human Geography: Some Reflections on the Diary-Photograph, diary-Interview Method', Environment \& Planning A, 35, 2003, pp. 1993-2017. H. Lorimer, 'Cultural Geography: The Busyness of Being More-than-Representational', Progress in Human Geography, 29, 2005, pp. 83-94.

${ }^{5}$ B. Anderson and P. Harrison, 'The Promise of Non-Representational Theories', in B. Anderson and P. Harrison, Taking-Place: Non-Representational Theories and Geography (Farnham: Ashgate, 2010), pp. 1-34. P. Vannini, 'NonRepresentational Research Methodologies: An Introduction', in P. Vannini, Non-Representational Methodologies: ReEnvisioning Research (New York: Routledge, forthcoming).

${ }^{6}$ Even though I believe that social and cultural geographies take place in more venues than the commonly-recognized 'geographical journals' my references in this paper almost exclusively pertain to those.

' P. Adler and P. Adler, 'Of Rhetoric and Representation: The Four Faces of Ethnography', The Sociological Quarterly, 49, 2008, 1-30.

${ }^{8}$ Lorimer, 'Cultural Geography', p. 84.

${ }^{9}$ Lorimer, 'Cultural Geography', p. 83.

${ }^{10}$ N. Thrift, Non-Representational Theory: Space, Politics, Affect (New York: Routledge, 2008), p. 2.

"B. Anderson and P. Harrison, Taking-Place: Non-Representational Theories and Geography (Farnham: Ashgate, 2010); P. Vannini, Non-Representational Methodologies: Re-Envisioning Research (New York: Routledge, forthcoming).

${ }^{12}$ D. Crouch, 'Flirting With Space: Thinking Landscape Relationally', Cultural Geographies, 17, 2010, 5-18.

${ }^{13}$ A. Latham, 'The Possibilities of Performance', Environment \& Planning A, 35, 2003, 1901-1906.

${ }^{14}$ P. 3 in N. Thrift, 'Performance And...'. Environment \& Planning A, 35, 2003, 2019-2024.

${ }^{15}$ P. 81 in N. Thrift, 'Summoning Life', in P. Cloke, P. Crang, and M. Goodwin, Envisioning Human Geographies (London: Arnold, 2004), 81-103.

${ }^{16}$ J.D. Dewsbury, 'Performative, Non-Representational, and Affect-Based Research', p. 324.

${ }^{17}$ Latham, 'The Possibilities of Performance', p. 1998.

${ }^{18}$ Latham, ibid. p. 2000.

${ }^{19}$ H. Thorpe and R. Rinehart, 'Alternative Sport and Affect: Non-Representational Theory Examined', Sport in Society, 13, 2010, 1268-1291.

${ }^{20}$ E. Laurier and C. Philo, 'Possible Geographies: A Passing Encounter in a Café', Area, 38, 2006, 353-363.

${ }^{21}$ S. Hinchcliffe, 'Performance and Experimental Knowledge: Outdoor Management Training and the End of Epistemology', Environment \& Planning D, 18, 2000, 575-595.

${ }^{22}$ S. Pink, Doing Sensory Ethnography (London: SAGE, 2009).

${ }^{23}$ T. Ingold (ed.), Redrawing Anthropology (Farnham: Ashgate, 2011).

${ }^{24}$ K. Stewart, 'Atmospheric Attunements', Environment \& Planning D, 29, 2011, 445-453. 
${ }^{25} \mathrm{~J}$. Wylie, 'Non-Representational Subjects?' in B. Anderson and P. Harrison, Taking-Place, pp. 99-115..

${ }^{26}$ Identifying reference.

${ }^{27}$ J.D. Dewsbury, 'Performative, Non-Representational, and Affect-Based Research'.

${ }^{28}$ E. Manning, 'Against Method', in P. Vannini Non-Representational Methodologies, forthcoming.

${ }^{29}$ M. Doel, 'Representation and Difference', in Anderson and P. Harrison, Taking-Place, pp. 117-130.

${ }^{30}$ Hinchcliffe, 'Performance and Experimental Knowledge'.

${ }^{31}$ H. Bergson, Key Writings (London: Continuum, 2002). M. Fraser, S. Kember, and C. Lury, 'Inventive Life: Approaches to the New Vitalism', Theory, Culture \& Society, 22, 2005, 1-14.

${ }^{32}$ P. 294 in P. Richardson-Ngwenya, 'Performing a More-Than-Human Material Imagination During Fieldwork', Cultural Geographies, 21, 2004, 293-299.

${ }^{33}$ P. 39 in B. Greenhough, 'Vitalist Geographies: Life and the More-than-Human', in B. Anderson and P. Harrison, Taking-Place, pp. 39-54.

${ }^{34}$ Greenhough, 'Vitalist Geographies'.

${ }^{25}$ P. 707 in A. Saldanha, 'Trance and Visibility at Dawn: Racial Dynamics in Goa's Rave Scene', Social and Cultural Geography, 6, 2005, 707-721,

${ }^{36}$ Ibid., p. 707.

${ }^{87}$ S. Saville 'Playing with Fear: Parkour and the Mobility of Emotion', Social and Cultural Geography, 9, 2008, 891914.

${ }^{38} \mathrm{I}$ am referring to performativity here in a broad pan-theoretical sense as the capacity to engage in performance.

${ }^{39}$ Laurier and Philo, 'Possible Geographies'.

${ }^{40}$ M. Rose, 'Pilgrims: An Ethnography of Sacredness', Cultural Geographies, 17, 2010, 507-524.

${ }^{41}$ Rose, "Pilgrims', p. 196.

${ }^{42}$ Latham, 'The Possibilities of Performance'.

${ }^{43}$ J.D. Dewsbury, 'Witnessing Space: Knowledge Without Contemplation', Environment \& Planning A, 35, 2003, 1907-1932.

${ }^{4}$ N. Thrift, Performance and...', Environment \& Planning A, 35, 2003, pp. 2019-2024. N. Thrift and J.D. Dewsbury, 'Dead Geographies and How to Make Them Live', Environment \& Planning D, 18, 2000, pp. 411-432. N. Wood, 'Playing with 'Scottishness': Musical Performance, Non-Representational Thinking, and the 'Doings' of National Identity', Cultural Geographies, 19, 2012, 195-215.

${ }^{45}$ S. Madison, Critical Ethnography: Method, Ethics, and Performance (London: SAGE, 2011).

${ }^{{ }^{16}}$ P. 187 in D. Conquergood, 'Rethinking Ethnography: Toward a Critical Cultural Politics', Communication Monographs, 58, 1990, pp. 179-194. 
${ }^{17}$ See Thrift, Non-Representational Theory.

${ }^{18}$ Stewart, 'Atmospheric Attunements'. K. Stewart, 'Road Registers', Cultural Geographies, 28, 2014, pages to be assigned.

${ }^{19}$ Stewart, 'Atmospheric Attunements', p. 445.

${ }^{50}$ Stewart, 'Atmospheric Attunements'.

${ }^{51}$ See for example J. Wylie, 'On ascending Glastonbury Tor', Geoforum, 33, 2002, 441-454. H. Lorimer and J. Wylie, 'LOOP (A Geography)', Performance Research, 15, 2010, 6-13.

${ }^{52}$ P. Simpson, 'Chronic Everyday Life: Rhythmanalysing Street Performance', Social and Cultural Geography, 9, 2008, 807-829.

${ }^{53}$ G. Reville, 'Performing French Folk Music', Cultural Geographies, 11, 2004, 199-209.

${ }^{54}$ Ibid., p. 202.

${ }^{55}$ A. Rogers, 'Geographies of Performing Scripted Language', Cultural Geographies, 17, 2010, 53-75.

${ }^{56}$ T. Ingold, The Perception of the Environment (London: Routledge, 2000). T. Ingold, Being Alive (London: Routledge, 2011).

${ }^{57}$ P. Vannini, D. Waskul, S. Gottschalk, The Senses in Self, Society, and Culture (New York: Routledge, 2011).

${ }^{58}$ P. Stoller, Sensuous Scholarship (Philadelphia: University of Pennsylvania Press, 1997).

${ }^{s 9}$ Stoller, Sensuous Scholarship, pp. xi-xii.

${ }^{60}$ I do not want to convey the impression that non-representational ethnography is an infinitely superior alternative to well-done, 'representational' ethnography. All forms of ethnographic work have their distinct objectives and merits. More simply, I want to emphasize the uniqueness of the non-representational style and its remarkable potential for tackling material evocatively.

${ }^{61}$ H. Lorimer, 'Surfaces and Slopes', Performance Research, 17, 2012, 83-86.

${ }^{62}$ N. Morris, 'Night Walking: Darkness and Sensory Perception in a Night-Time Landscape Installation', Cultural Geographies, 18, 2011, 315-342.

${ }^{63}$ L. Hill 'Archaeologies and Geographies of the Post-Industrial Past', Cultural Geographies, 20, 2013, 379-396.

${ }^{67}$ M. Buscher, J. Urry, and K. Witchger (Eds.), Mobile Methods (London, Routledge, 2010). D. DeLyser and D. Sui, 'Crossing the Qualitative-Quantitative Divide II: Inventive Approaches to Big Data, Mobile Methods, and Rhythmanalysis', Progress in Human Geography, 37, 2013, 293-305.

${ }^{65}$ P. 16 in K. Simonsen, 'In Quest of a New Humanism: Embodiment, Experience, and Phenomenology as Critical Geography', Progress in Human Geography, 37, 2013, 10-26.

${ }^{66}$ Ingold, Being Alive.

${ }^{67}$ T. Ingold, Lines: A Brief History (London: Routledge, 2007) p. 75. 
${ }^{68}$ J. Wylie, 'Glastonbury Tor'. J. Wylie, 'A Single Day's Walking: Narrating Self and Landscape on the South West Coast Path', Transactions of the Institute of British Geographers, NS 30, 2005, 234-247.

${ }^{69}$ A. Lingis, 'Irrevocable Loss', in P. Vannini, Non-Representational Methodologies.

${ }^{70}$ Stewart, 'Road Registers'.

${ }^{71}$ H. Lorimer and J. Wylie, 'LOOP (A Geography)', Performance Research, 15, 2010, 6-13.

${ }^{72}$ P. 96 in T. Cresswell, 'Non-Representational Theory and Me: Notes of an Interested Sceptic', Environment \& Planning D, 30, 2012, 96-105. 